\title{
LA “VERDADERA EFICACIA" DE LA MEMORIA EN EL TRASTORNO DEL ESPECTRO AUTISTA
}

\author{
The "truly efficiency" in the memory in Autistic Spectrum Disorders
}

Sandra Cañote García*

\begin{abstract}
Resumen
Este artículo expone información reciente sobre el funcionamiento de los sistemas de memorias en las personas con trastorno del espectro autista (TEA). Con respecto a la memoria semántica, las personas con TEA logran un adecuado rendimiento, mientras que la memoria episódica o autobiográfica, se manifiesta en desventaja. Al parecer existe una asociación inapropiada entre ambas, es decir las personas con TEA son capaces de tener conocimiento sobre el mundo y evocar dicha información, pero, no logran recordar los hechos relacionados consigo mismos.
\end{abstract}

Palabras clave: Trastorno del espectro autista, memoria, memoria semántica, memoria episódica o autobiográfica.

\begin{abstract}
This article exposes recently information about the function of the memory systems in persons with autism spectrum disorders. About the semantic memory, persons with ASD make a suitable performance, how about the episodic or autobiographical memory shows disadvantage. We can say that exists an inappropriate association between both memories, the persons with ASD have knowledge of the world and evoke this information, but they cannot remember facts in relation with themselves.
\end{abstract}

Key words: Autism spectrum disorders, memory, semantic memory, episodic or autobiographical memory.

\footnotetext{
* Licenciada en Psicología, Especialista en Audición, Lenguaje y Aprendizaje, Magíster en Fonoaudiología, Candidata al Doctorado en Psicología por la Universidad Femenina del Sagrado Corazón. sandracg_psi@yahoo.es
} 
Como indica Martos-Pérez y Paula-Pérez (2011), el trastorno del espectro autista (TEA) es el término que se emplea para explicar las distintas manifestaciones de gravedad del autismo.

Asimismo, quienes desarrollan en la práctica clínica, la evaluación y el diagnóstico de estos cuadros, reportan que el motivo de consulta se centra en la alteración de la comunicación y del lenguaje, aspectos típicos de esta población, además, de la alteración cualitativa en la interacción social y, la presencia de patrones de comportamientos, intereses y actividades, restringidas y estereotipadas (Martos y Ayuda, 2002).

También se sabe que los TEA, como lo estableció Wing y Gould en 1979 (Gillberg, 2006), responden a una noción dimensional de continuo, en la que además de estar alteradas la interacción social y la comunicación, se encuentra afectada la capacidad de imaginación.

Autores como, Baron - Cohen en 1995 (Ruggieri y Valdez, 2011), Rivière (1997) y Frith en 1999 (Ruggieri y Valdez, 2011), han proporcionado a este concepto una profunda investigación, lo cual determina que los supuestos teóricos que iniciaron Kanner (1943) y Asperger (1944), han evolucionado significativamente en las últimas décadas, entregando a la comunidad científica constructos cognitivos que han permitido comprender el funcionamiento psicológico de los TEA.

A estos constructos, que refieren las dificultades en la teoría de la mente, en las funciones ejecutivas y en la coherencia central, se vienen sumando, como lo describe Solcoff (citado en Ruggieri y Valdez, 2011), aquellos estudios que buscan dar un modelo teórico capaz de enmarcar el verdadero funcionamiento de la memoria en el espectro autista. Pues, cuando Kanner y Asperger realizaron las descripciones de sus casos clínicos, destacaban la buena memoria de sus pacientes, en la actualidad, las investigaciones han mostrado que no todas las funciones de la memoria en las personas con TEA, consignan ese "eficaz desempeño".

\section{LA MEMORIA}

Frank y Landeira-Fernandez (2006) refieren que la memoria es un proceso cognitivo, estructurado por un conjunto de operaciones que integran al medio ambiente y que poseen sustratos neurales específicos. La memoria es la responsable en colocar en el presente, lo pasado.

Por otra parte, Baddeley en el año 2000 (citado en Frank y Landeira-Fernandez, 2006), luego de la revisión de estudios previos, propuso un modelo funcional para la memoria, determinando que después de un registro sensorial, un estímulo se puede almacenar por la acción de una memoria operativa (a corto plazo) o por la de una memoria permanente (a largo plazo). En esta memoria permanente, se ubican, la memoria procedimental y la declarativa y, en ésta última, la semántica y la episódica o autobiográfica.

Estos dos tipos de memoria (semántica y episódica), han sido contrastados tradicionalmente desde las investigaciones realizadas por Tulving en el año 1983 (Ruiz-Vargas, 2000) y, aunque existen desde la neurociencia, sólidas razones para creer que la memoria semántica y la episódica no constituyen sistemas tan independientes como se creía en un inicio, la distinción ha sido extremadamente influyente y útil para organizar los fenómenos, tareas y modelos de la memoria en las investigaciones sobre los TEA.

Por otra parte, cuando se habla de memoria, es necesario comprender sus procesos. El primero de ellos, es determinado por la codificación que, mediante la calidad del proceso perceptivo y de la profundidad cómo organiza el material que ingresa, puede formar una huella mnésica, de forma algo estable. Luego, el proceso de almacenamiento, que implica el sostenimiento de la información codificada en el tiempo, conservándola y, de algún modo, previniendo su olvido. Y, por último, el proceso de recuperación, que refiere la actualización de la información almacenada para poder ser utilizada.

La recuperación de las huellas mnésicas puede realizarse por evocación libre o con ayuda de claves de recuperación, que facilitarían la evocación o por reconocimiento, es decir por la confrontación con el material almacenado (Margulis, 2009).

Las personas con TEA, aparentemente, lograrían en base a un recuerdo libre, la recuperación de datos anteriormente almacenados y cuyos contenidos 
no lo involucren directamente. Pues, cuando el recuerdo implica su propia historia o la narración de experiencias personales, los resultados se registrarían de una manera irregular que, ni con el uso de claves de recuperación, alcanzarían la evocación. El análisis de Ruiz-Vargas (2000) podría revelar las posibles razones de esta peculiaridad, al referir que existe una memoria capaz de efectuar la propia biografía del individuo cuando su yo interacciona con el mundo, aprendiendo de sí mismo, mientras este yo, actúa. Y, es precisamente esta respuesta del yo con el mundo, en función a la interacción dinámica y sin restricciones, la que no lograría acrecentarse en las personas con TEA, determinando por lo tanto, sus dificultades no sólo para recuperar experiencias, sino también, para desarrollar una conciencia coherente sobre su identidad personal.

Por lo tanto, las personas con TEA, lograrían aprender, almacenar lo aprendido y hacer uso de ello. Lo que no pueden es recordar. Y, recordar, que proviene del latín re-cordis, refiere por un lado "re", algo que vuelve a ser en el tiempo y, por otro, "cordis", significa corazón. De tal forma, en su significado original, haría referencia a "volver a pasar por el corazón".

El valorar la semántica del verbo recordar, como lo dice Solcoff (citado en Ruggieri y Valdez, 2011), permite recoger su dimensión afectiva. Sin embargo, siguiendo en este plano léxico-semántico, podemos hallar que no sólo el corazón es responsable de los recuerdos, sino también, la mente. Así, el verbo en inglés remember, atañe a la mente, como responsable de la función de evocación.

Este sencillo análisis lingüístico, sugiere que "corazón" y "mente" pueden relacionarse cómodamente, al momentode reproducir los contenidos de la memoria y además, supone la presencia de los llamados procesos cognitivos cálidos, responsables de la comprensión del mundo subjetivo.

Por ello, volviendo a las personas con TEA, su recuerdo es pobre y no focalizada en los aspectos subjetivos, emocionales e interpersonales de los eventos. Su recuerdo se encuentra subordinado al "aquí y ahora" y no a la posibilidad de desplazarse mentalmente al pasado.
Es por esto, que las personas con un diagnóstico de TEA, recuerdan menos eventos y parecen estar dominados por aspectos más concretos, más perceptuales de la experiencia.

\section{LA MEMORIA SEMÁNTICA EN LAS PERSONAS CON TEA}

Tulving en 1995 (Margulis, 2009) refirió que la memoria semántica es la que da soporte al conocimiento. Se encuentra ligada al lenguaje, a los hechos, a los conceptos y a la información general del entorno, sin considerar las dimensiones espaciales ni temporales.

Para comprender aún más lo que es la memoria semántica, se debe comenzar con la memoria a largo plazo que, es un almacén al cual se apela cuando comúnmente se habla de la memoria, en un término general. Es en donde se acumulan conocimientos acerca del mundo, conceptos, imágenes, etc.

Se la considera como la base de datos en la que se inserta la información a través de la memoria operativa, para poder posteriormente hacer uso de ella.

Lo que se conoce como memoria semántica, es entonces, un almacén de conocimientos acerca de los significados de las palabras y las relaciones entre estos significados, constituyendo una especie de diccionario mental.

Ahora bien, los estudios que han abordado su funcionamiento en las personas con TEA, refieren su adecuado manejo. Toichi y Kamio (2001), por ejemplo, hallaron buen desempeño en tareas de asociaciones de palabras, lo cual sugería, el apropiado nivel de procesamiento, es decir el uso conveniente de este diccionario mental. No obstante, los mismos autores, en una nueva investigación (2003), si bien reconocieron la memoria semántica, intacta en las personas con TEA, identificaron una relación defectuosa con la memoria episódica. Es decir, los sujetos autistas no podrían ayudarse de su correcta memoria semántica, al momento de enfrentar tareas de memoria episódica, lo cual finalmente generaría en su discurso, inconvenientes al procesar la información de su almacén mental. 


\section{LA MEMORIA EPISÓDICA O AUTOBIOGRÁ- FICA EN LAS PERSONAS CON TEA}

La memoria autobiográfica, señala Solcoff (citado en Valdez, 2001) es un constructo que se encuentra unido al concepto del self, y quien haciendo mención a Baddeley (1992) la reconoce como la capacidad de los seres humanos para recordar sus vidas. Asimismo, implica mecanismos y procesos cognitivos comprometidos en el reconocimiento de diversos eventos de la vida propia, como también, de factores sociales y emocionales que favorecen a la construcción del self.

La organización de los contenidos en la memoria episódica está sujeta a parámetros espacio-temporales; esto es, los eventos que se recuerdan representan los momentos y los lugares en que se presentaron.

Dicho de otro modo, la perspectiva del tiempo es la "mirada" sobre los acontecimientos de la propia vida. Y, es en la búsqueda de un pasado olvidado, donde se descubre el hecho de un sí mismo, que posee la capacidad de representar y de representarse (Azzollini y González, 2006).

Esta forma de memoria puede ser "viva y exacta", especialmente cuando la gente la estima como muy importante.

Igualmente, la memoria episódica, no es un sistema de memoria per se, sino como ya se indicó, un sistema de memoria del self, que emerge de la interacción entre la base del conocimiento autobiográfico y la construcción de ese self actual.

Conway y Holmes (citado en Azzollini y Gonzáles, 2006) agregaron que la memoria episódica o autobiográfica es duradera, específica y de significación para el concepto de uno mismo, es decir, para la identidad personal.

Entonces, acercándose a los TEA, Solcoff (citado en Valdez, 2001) se pregunta: "¿qué ocurre con la memoria autobiográfica cuando el desarrollo del 'sí mismo' se encuentra alterado?, ¿cómo es procesada la información relativa al 'sí mismo' cuando éste no ha podido llegar a constituirse para el propio sujeto?" (p. 155).
En este artículo, los trabajos de Powell y Jordan (1993) intentan responder a estas interrogantes, precisando que el desarrollo de los recuerdos episódicos, se da gracias a lo que el self experimenta, a la manera cómo se concibe a "sí mismo" y al nivel de implicación, no sólo con los demás, sino consigo mismo.

Por lo tanto, esta memoria episódica o autobiográfica en las personas con TEA, ha sido muy investigada en los últimos años, pues se convierte en otro constructo que, también podría dar una explicación sobre el funcionamiento neuropsicológico en este cuadro.

Estudios, a lo largo de la vida de las personas con espectro autista, como es el caso de la investigación de Crane y Goddard (2008), encontraron en las personas adultas, específicamente con síndrome de Asperger, dificultades para recuperar eventos en el periodo de la adolescencia y en el inicio de la adultez, época en la que, naturalmente, se realiza un incremento en el número de evocación de recuerdos y que constituirían la formación de la identidad adulta y de la construcción de metas futuras.

Igualmente, en esa misma dirección, otros trabajos experimentales encontraron en las personas con TEA dificultades en las pruebas de evaluación de experiencia subjetiva, en las de recuerdo libre y en las que se encontraban ausentes claves semánticas o las que requerían de cognición temporal (Solcoff, 2011).

\section{CONCLUSIONES}

Han pasado casi siete décadas desde que Kanner y Asperger efectuaran sus descripciones clínicas y con ellas, un cúmulo de trabajos que han permitido propuestas explicativas e interpretativas alrededor de los trastornos del espectro autista.

De estos trabajos, se han desprendido constructos que son aceptados actualmente, como las bases neurobiológica y neuro-psicológicas de estos trastornos (Ruggieri y Arberas, 2007).

Así, además de la teoría de la mente, de las funciones ejecutivas y de la coherencia central, en los últimos años se viene desarrollando estudios que 
dan una explicación sobre el funcionamiento de la memoria en las personas con TEA, determinando que, lo que en un comienzo los pioneros, Kanner y Asperger, consideraban como "excelente", en el presente identifican que la memoria, en las personas con TEA, establece un perfil particular de fortalezas y debilidades, de manera tal que, algunos procesos en este funcionamiento cognitivo, muestran alteraciones y otros, se encontrarían preservados.

De esta forma, una persona con TEA revelará buen rendimiento cuando el ejercicio se realiza sobre los conocimientos lingüísticos y culturales, pero, que no requiera de la referencia personal, de ese self, que permite "revivir" el recuerdo, efectuar un "viaje mental" y construir una identidad y objetivos futuros.

Las investigaciones sobre los TEA han sido significativas, en las últimas décadas, sobre todo alrededor de los ejes que caracterizan dichos cuadros (triada Wing). No obstante, el estudio del funcionamiento de la memoria en los TEA, se ha convertido en los últimos años, en objeto de diversos planteamientos teóricos que, por un lado, se orientan a la evolución del self, y por otro, a las habilidades representacionales y al rol del procesamiento cognitivo, en las funciones de codificación y de recuperación de las memorias.

Asimismo, este desarrollo científico no sólo contribuye a la comprensión del mundo mental de las personas con espectro autista, sino también otorga a los involucrados en su tratamiento, herramientas que les puedan ser útiles para la organización biográfica de su yo, a las exigencias de su ambiente.

Por ello, como bien decía Rivière (1997), debemos incrementar nuestros conocimientos pues los trastornos del espectro autista nos desafían. No debemos quedarnos en la fascinación que implican sus manifestaciones conductuales, sino debemos apropiarnos de todo entendimiento que nos acerque a su mente y a la manera como procesan las sutilezas que ofrece el entorno, para después, como también lo decía Rivière, "abrir puertas" y ofrecerles las posibilidades de reconocerse y admitir a los que lo rodean.

\section{REFERENCIAS}

Asperger, H. (1944). Die autistischen psychopaten im kindesalter [Psicopatía autista en la infancia]. Archiv Für Pschiatrie und Nervenkrankheiten, 117, $76-136$.

Azzollini, S. y González, F. (2006). La localización temporal de recuerdos autobiográficos. Anuario de Investigaciones, 14, 19-27.

Crane, L. y Goddard, L. (2008). Episodic and semantic autobiographical memory in adults with autism spectrum disorders. Journal of Austim and developmental disorders, 38(3), 498-506.

Frank, J. y Landeira-Fernandez, J. (2006). Rememoração, subjetividade e as bases neurais da memória autobiográfica. Revista Psicologia Clinica, 18(1), 35-47.

Gillberg, C. (2006). A guide to Asperger syndrome. United Kingdom: Cambridge, University Press.

Kanner, L. (1943). Autistic disturbances of affective contact. Nervous Child.. 2, 217-250.

Margulis, L. (2009). Funcionamiento de los sistemas de memoria en niños con trastorno autista y trastorno de Asperger. Revista Argentina de Neuropsicología, 13, 29-48.

Martos-Pérez, J. y Paula-Pérez, I. (2011). Una aproximación a las funciones ejecutivas en el trastorno del espectro autista. Revista Neurológica, 52(1), 147-153.

Martos, J. y Ayuda, R. (2002). Comunicación y lenguaje en el espectro autista: el autismo y la disfasia. Revista Neurológica, 34(1), 58-63.

Rivière,A.(1997). Tratamientoy definición delespectro autista I: relaciones sociales y comunicación. Madrid, España: APNA-IMSERSO.

Ruggieri, V. y Arberas, C. (2007). Trastornos generalizados del desarrollo. Aspectos clínicos y genéticos. Revista Actualizaciones en Neurología Infantil, 67(1), 569-585.

Ruggieri, V. y Valdez, D. (2011). Autismo, del diagnóstico al tratamiento. Buenos Aires, Argentina: Paidós. 
Ruiz-Vargas, J. (2000). Claves de la memoria. Madrid, España: Editorial Trotta.

Toichi, M. y Kamio, Y. (2001). Verbal association for simple common words in high functioning autism. Journal of Autism and Developmental Disorders, 31(5), 483-490.

Toichi, M. y Kamio, Y. (2003). Long - term memory in high - functioning autism: controversy on episodic memory in autism reconsidered. Journal of Autism and Developmental Disorders, 33(2), 151-161.

Valdez, D. (2001). Autismo: enfoques actuales. Una guía para padres y profesionales de la salud y la educación. Buenos Aires, Argentina: Fundec.

Fecha de recepción: 6 de enero de 2012

Fecha de aceptación: 10 de agosto de 2012 